\title{
O STATVS JURÍDICO SVI GENERIS DOS ANIMAIS NO CORPVS IVRIS CIVILIS
}

\section{THE SUI GENERIS LEGAL STATUS OF ANIMAL IN THE CORPUS IURIS CIVILIS}

\section{HERON JOSÉ DE SANTANA GORDILHO}

Pós-Doutor pela Pace University Law School, Nova York. Doutor em Direito na Universidade Federal de Pernambuco. Professor do PPGD/UFBA e do PPGD/UCSAL. Membro da World Academy of Art \& Science (WAAS). Promotor de Justiça em Salvador/BA.

\section{CRISTÓVÃO JOSÉ DOS SANTOS JÚNIOR}

Mestrando em Literatura e Cultura pela Universidade Federal da Bahia (UFBA). Pesquisador do Núcleo Interdisciplinar de Pesquisa e Extensão em Direito Ambiental e Direito Animal (NIPEDA).

\section{RESUMO}

Este artigo utiliza o método hermenêutico visando traduzir e interpretar o sentido correto do status jurídico dos animais na tradição do Direito Romano a partir das Institutiones do Corpus luris Ciuilis. Dessa forma, o artigo questiona a tradicional e reducionista visão de a tradição do Direito Romano sempre considera os animais como coisa. Inicialmente, o artigo faz um breve resumo histórico do Direito Romano à época da criação da obra justinianeia. Em seguida, promove uma tradução de trechos das Institutas que fazem referência aos animais diretamente de uma versão em Latim do romanista alemão Paulus Krueger, momento em que são explicitados traços que indicam que os animais gozavam de um status jurídico singular nas Institutiones. Por fim, constata que existe uma diferença de tratamento entre os animais naquele documento, em decorrência da própria animalidade e da vontade 
dos animais, que são classificados segundo diferentes critérios, tais como natureza e hábito, que ensejam diferentes categorias, uma vez que os animais possuem direitos derivados do ius naturale.

PALAVRAS-CHAVE: Institutas; Justiniano; Animais; Res; Coisa.

\begin{abstract}
It is studied the animal's legal status in the Corpus luris Ciulis Institutiones. Therefore, it is questioned the traditional and reductionist way of thinking that identifies those being simply as things, evidencing clues to sui generis character, through a rereading of the Institutes. To such end, the required Roman Law's history to understand Justinian's work is retrieved. Then, a translation proposition for Institutes' parts which have any animal reference is presented, at which point are shown plentiful of signs that point to a singular law condition. It is realized, upon that, a difference in treatment based on animals' own animality and will, distinguished and classified according to different standards, such as nature and habits, like the categories of domestic, wild, domesticated, and non-domesticated animals. Therefore, clues that disclose acknowledgment of animals' sentience and that these beings truly had right derived from ius naturale are revealed.
\end{abstract}

KEYWORDS: Institutes; Justinian; Animals; Res; Thing.

\title{
INTRODUÇÃO
}

O presente artigo analisará o status jurídico dos animais nas Institutiones do Corpus luris Ciuilis, para encontrar indícios de que a tradição do Direito Romano já considerava que, em determinadas situações, os animais já gozavam de um status jurídico diferente do status jurídico de coisa ou bem jurídico de valor econômico.

Para Gadamer a tradução, como qualquer atividade de compreensão humana, acontece por meio da interpretação, de modo que esta pesquisa utilizará o 
método hermenêutico, visando interpretar o sentido correto do status jurídico dos animais na tradição do Direito Romano a partir das Institutiones do Corpus luris Ciuilis.

Embora os manuscritos originais das Institutas do século VI tenham se perdido, trabalhou-se com uma versão em Latim mais original possível: a célebre edição do romanista alemão Paulus Krueger, apresentando uma proposta de tradução, para fins didáticos, voltada efetivamente para a compreensão jurídica do objeto desse estudo.

É que são escassos os estudos nesse sentido e, ainda que existam pesquisas sobre a compilação justinianeia, o mundo jurídico ainda se ressente de investigações sobre as raízes históricas do status jurídico dos animais na tradição do Direito Romano.

A primeira parte deste artigo não se pretenderá reescrever a história do Direito Romano, mas apenas fazer um breve resumo do Direito Justinianeu apresentando as condições sociais e políticas que ensejaram a elaboração do Corpus luris Ciuilis.

Em seguida, Este artigo irá traduzir e interpretar as Institutas, trazendo à tona pistas que vêm sendo ignoradas pela doutrina, especialmente o fato de que em Roma, em determinadas circunstâncias, os animais eram considerados sujeitos de direito.

A partir de traduções dos textos originais, o artigo irá uma analisar o status jurídico dos animais no ius naturale, e em seguida os modos de aquisição da propriedade animal, a reaquisição da liberdade pelos animais selvagens e a aquisição da liberdade pelos animais domesticados.

\section{O MOMENTO POLÍTICO DA INSTITUIÇÃO DO CORPUS IURIS CIUILIS}

O estudo do Direito Romano diz respeito à análise de instituições de direito privado, a denominada "história interna do Direito Romano", também conhecida como historia iuris (CAMPELLO, 1929, p.30) que se divide em período pré-clássico (753 a.C. a 130 a.C.), período clássico (130 a.C. a 230 a.C.), período pós-clássico 
(230 a.C a 530 a.C.) e período Justinianeu (530 a.C a 565 a.C.), à qual se contrapõe a "história externa" ou antiquitates iuris, que é um o estudo detalhado das jurisprudências, das instituições políticas e das inúmeras fontes do Direito Romano.

Como sabemos, o Estado Romano adotou diferentes formas de governo, tais como a Monarquia, a República, o Principado e o Dominato. Nesse sentido, impende frisar que o direito justinianeu, em sua dimensão externa, localiza-se no período do Dominato e, em sua dimensão interna, no período pós-clássico (PEIXOTO, 1997, p.4).

A fim de resolver os problemas administrativos decorrentes da enorme extensão do Império Romano, Diocleciano decide dividi-lo em dois: o Império Oriental e o Império Ocidental, cada uma governada por um Augusto, com um Caesar como lugar-tenente, totalizando o número de quatro governantes (ALVES, 2016, p.43-44).

Após Diocleciano, Constantino se destaca durante o Dominato (TELLEGENCOUPERUS, 2003, p.117-118), por reunificar o Império Romano e transferir a capital para Bizâncio, que passa a chamar-se Constantinopla (PEIXOTO, 1997, p.108). Constantino converte-se ao cristianismo e elabora o Édito de Milão, autorizando a prática cristã em solo romano, um dos fatores que contribuirão com a humanização do Direito, a despeito de provocar uma crise no escravismo (MARTINS, 2011, p.202) e o próprio declínio do Império (GIORDANI, 1991, p.20-21).

É importante destacar que no Dominato, o imperador é considerado dominus e Deus (ALVEZ, 2016, p.44), já que ao mesmo tempo em que atua como governante supremo, concentra poderes de ordem religiosa, (LOPES, 2013, p.27) um fenômeno denominado de cesaropapismo.

Com o poder absoluto nas mãos do imperador, tanto a Magistratura quanto 0 Senado se enfraquecem, de modo que os Senados - tanto o de Roma quanto o de Constantinopla - passam a exercer uma mera função de conselho municipal, ao passo que a Magistratura se torna uma espécie de Consulado honorífico ou pretura urbana, sem qualquer jurisdição, promovendo apenas jogos para o público ou atuando como Tribunato da Plebe (PEIXOTO, 1997, p.109).

Como fontes do direito destacam-se as constituições imperiais, intituladas leges, que podem ser leges generales (normas de caráter geral), reescritos 
(medidas particulares) ou sanctio pragmatica (lei geral elaborada a pedido de um alto funcionário), além do costume, utilizado para o preenchimento das lacunas jurídicas (ALVES, 2016, p.45). Além disso, as normas decorrentes das fontes de direito de períodos anteriores continuam vigentes, desde que não tenham sido revogadas (PEIXOTO, 1997, p.110).

Acontece que essa atividade jurisprudencial entra em crise, já que as antigas normas passam a ser conhecidas muito mais pelas obras dos jurisconsultos clássicos do que pela análise direta das fontes originais. Assim, o Direito contido nessas obras clássicas passa a ser denominado de iura, de modo que as fontes do direito passam a ser as leges e os iura (SCHILLER, 1978, p.395).

Os iura, porém, provocam várias controvérsias, porque muitos advogados começam a manipular os dados e a falsear as citações dos jurisconsultos clássicos, fazendo com que a insegurança jurídica se alastre pelos tribunais. Visando a limitar a invocação dos iura, os imperadores Teodósio II e Valentianiano III ordenam a elaboração da Lei das Citações, segundo a qual somente podem ser admitidos em juízo os escritos dos jurisconsultos Modestino, Papiniano, Gaio, Ulpiano e Paulo (ALVES, 2016, p.46).

Não obstante, após o período clássico do Direito Romano, marcado pelo esplendor de ideias inovadoras e pelo alvorecer jurídico decorrente da atividade dos jurisconsultos, a partir do século III vamos assistir a uma época de decadência que culmina com uma grande crise no Império Romano seguida da "Queda do Império do Ocidente" em 476 (CRETELLA JÚNIOR, 1971, p.42).

Esta decadência imperial não vai ocorrer de forma abrupta, como sugere o vocábulo "queda", mas na forma continuada de uma crise sistêmica, complexa e prolongada, e ao lado dessa crise político-econômica vai ocorrer também um grande declínio jurídico, devido ao afastamento temporal dos prudentes clássicos, mas também devido ao excesso de leges e do gradual processo de alteração linguística, tendo em vista que as modificações sofridas pelo latim criam uma Babel normativa que torna muito difícil a interpretação do Direito.

É que as normas jurídicas começam a proliferar de tal modo que o Império assiste ao surgimento de inúmeras dúvidas a respeito das normas efetivamente 
vigentes, o que leva à vulgarização do Direito e ao afastamento cada vez maior entre as normas jurídicas e as normas efetivamente aplicadas (ALVES, 2016, p.47).

Para enfrentar este problema, fez-se necessária a reunião do acervo normativo das compilações pré-justinianeias anteriores ao Corpus luris Ciuilis, tais como as leges e os Códigos Gregoriano, Hermogeniano e Teodosiano, pois além das leges e dos iura, existiam a Lei Romana dos Visigodos, a Lei Romana dos Burgúndios e o Edito de Teodorico (CRETELLA JÚNIOR, 1971, p.43-44).

$\mathrm{Na}$ tentativa de superar esta decadência jurisprudencial, o século $\mathrm{V}$ apresenta-se como um momento de ressurgimento de estudos jurídicos sobre os autores clássicos e as instituições do Império Romano do Oriente, com destaque para a Escola de Berito, e é este momento político vai permitir a elaboração, na primeira metade do século VI, do Corpus luris Ciuilis, publicada entre os anos de 529 e 534 a.C.

\section{O CORPUS IURIS CIUILIS COMO FONTE DO DIREITO ROMANO JUSTINIANEU}

Com a morte do imperador Justino, em 527 d.C., ascende ao trono seu filho adotivo Upranda (MEIRA, 1983, p.78), originário da Trácia e natural de Tauresium (Taurésio) (FRÓES, 2004, p.56), nascido em 482 d.C. e filho biológico de Sabatio e Vicleniza. Esse homem inculto e de origem humilde, que nunca havia visitado Roma, muda seu nome eslavo para lustinianus e, com grande concentração de poder, inicia uma fase militarista de expansão do Império Romano Oriental, reinando por 39 anos até a sua morte em 565 d.C., aos 83 anos de idade (CRETELLA JÚNIOR, 2007, p.50)..

Justiniano restabelece o domínio romano em parte da península itálica, expulsa os ostrogodos da África, além de submeter os vândalos ao seu poder. $\mathrm{Na}$ Espanha derrota os visigodos e com mãos de ferro impõe sua vontade em um reinado absoluto legitimado pela religião, de modo que tudo que agrade ao príncipe passa a ter força de lei (quod principi placuit, legis habet uigorem) (MEIRA, 1983, p.73). 
O império justinianeu é marcado por um importante reflorescimento cultural, com grande produção de esculturas, pinturas, mosaicos, obras literárias e monumentos arquitetônicos - como a Basílica de San Vitale, em Ravenna, e a Igreja de Santa Sofia, em Constantinopla -, além da edição de seu legado mais importante: o Corpus lurius Ciuilis (PEIXOTO, 1943, p.119).

A grande obra jurídica justinianeia vai ser formada por cinco livros: Institutas, Digesto, dois Códigos e Novelas (CASTRO, 2007, p.86) embora somente em 1.538 d.C. esse conjunto tenha sido batizado pelo romanista francês Dionysius Gothofredus (Dionísio Godofredo) de Corpus luris Ciuilis (VÉRAS NETO, 2011, p.139) expressão que já era usada pelos glosadores entre os anos 1.100 e 1.250 d.C. para designar o Direito Romano em geral, em oposição ao Direito Canônico, conhecido por Corpus luris Canonici (CRETELLA JÚNIOR, 2004, p.51).

Muitos consideram essa obra o grande legado romano para o Direito, mas a sua elaboração somente se deu após a queda do Império Romano do Ocidente em 476 d.C. e a deposição do imperador Rômulo Augusto pelo bárbaro Odoacro, Rei dos Hérulos (LUIZ, 1981, p.37). Editado na Roma Oriental, o Corpus luris Ciuilis teve o importante papel de resgatar e consolidar os alicerces jurídicos estabelecidos pelo Império Romano Ocidental (ALVES, 2016, p.49).

Como Justiniano é herdeiro de um sistema burocrático bastante complexo e legislativamente desorganizado, a despeito de todos os trabalhos previamente empreendidos como as compilações pré-justinianeas, fez-se necessária uma sistematização normativa das leis vigentes na época (STEIN, 2004, p.33).

De fato, em um contexto em que existem diversas leis esparsas, pairando sérias dúvidas sobre quais delas estão vigentes, o imperador nomeia, em 528 d.C., uma comissão formada por dez membros, dentre eles Teófilo, professor da Escola de Constantinopla (MARTINS, 2011, p.209).

Justiniano pretende compilar as constituições imperiais vigentes (leges), para facilitar a aplicação do direito, e refundir os códigos anteriores (Gregoriano, Hermogeniano e Teodosiano), excluindo repetições, contradições e a aplicação de leges revogadas (MOUSOURAKIS, 2012, p.73). 
Fruto do empenho da comissão liderada por Triboniano, ministro da justiça de Justiniano, nasce o Nouus lustinianus Codex, que foi solenemente promulgado em 7 de abril do ano de 529 d.C (RADDING, 2007, p.35).

Não obstante, embora as leges fossem finalmente agrupadas (CRETELLA JÚNIOR, 2004, p.51), a falta a sistematização dos iura fez surgir várias controvérsias jurídicas em razão das divergências entre os iura derivados dos pareceres dos jurisconsultos clássicos, o que leva Justiniano a elaborar as Cinquenta Constituições (Quinquaginta Decisiones) com o objetivo de sanar essas antinomias (ALVES, 2016, p.49).

Em 530 d.C., porém, ao notar que suas leges são insuficientes e que os iura precisam ser urgentemente sistematizados para reduzir a insegurança jurídica, o imperador nomeia uma nova comissão, formada por 16 membros e chefiada mais uma vez por Triboniano, para reunir e unificar os pareceres dos antigos jurisconsultos ou prudentes. Assim, após o estudo de quase dois mil livros em apenas 03 anos, surgem 533 d.C. (MEIRA, 1983, p.80), o Digesto (Digesta) ou Pandectas (Pandectae) (CRETELLA JÚNIOR, 2004, p.52).

Acontece que entre o Nouus lustinianus Codex e o Digesta vão surgir inúmeras controvérsias, uma vez que as comissões anteriormente constituídas estavam mais preocupadas em compilar o direito existente do que em atualizá-lo.

Justiniano, firme na crença de que sua obra é sublime e perfeita, proíbe qualquer tipo de comentário ao seu texto e considera as críticas como perversões (immo magis peruersiones), permitindo apenas a elaboração de sumários (índices) ou traduções literais do seu texto para o grego, de modo que aquele que venha a desobedecer essa ordem ou citar em juízo outra obra que não o Códex, o Digesto ou as Institutas, será considerado um falsário e terá os seus escritos destruídos (PEIXOTO, 1943, p.117).

Justiniano nomeia uma nova comissão, dessa vez formada por cinco membros, e determina que seja feita uma profunda atualização do Codex, o que culmina na promulgação, em 534 d.C., da nova edição do Codex repetitae praelectionis, que revoga o antigo Código (MEIRA, 1983, p.82).

A realidade jurídica, porém, continua sofrendo transformações, o que faz surgir a necessidade de promulgação de novas constituições imperiais (CRETELLA 
JÚNIOR, 2004, p.53). O próprio Justiniano, tendo em vista a incessante busca por sistematização jurídica, promete elaborar uma compilação à parte dessas novas leges (alia congregatio), o que nunca veio a se efetivar em seu governo.

Essas constituições imperiais, após a morte de Justiniano, vão ser reunidas em um corpo único e traduzidas para o grego e o latim (MEIRA, 1983, p.82), e se tornam conhecidas como Nouellae Constitutiones ou, na forma resumida, Nouellae (Novelas), divididas em prefácio, capítulo e epílogo (PEIXOTO, 1943, p.118).

Após a elaboração do Digesto, Justiniano escolhe três grandes juristas (seu ministro, Triboniano; Doroteu, professor em Berito e Teófilo, professor em Constantinopla) para elaborarem um manual didático com vistas à melhor compreensão das Pandectas. Essa comissão, utiliza como modelo as Institutas de Gaio e fazendo uso das Res Cottidianae, do Digesto e do Codex de 529, elabora as Institutas de Justinano, que entram em vigor na mesma data que as Pandectas, isto é, em 30 de dezembro de 533 d.C (ALVES, 2016, p.49).

Destaque-se, ademais, que as Institutiones estão divididas em quatro livros, os quais, a seu turno, estão subdivididos em títulos e parágrafos, além de um proêmio (principium) (CRETELLA JÚNIOR, 2004, p.53), e embora direcionadas ao ensino, possuem um valor autônomo de lei (PÔRTO,1962, p.31-34), sendo, inclusive, invocadas nos tribunais.

Assim, as institutas ou Institutiones são na verdade manuais didáticos que visam ao ensino do Direito Romano, com destaque para duas delas: a Gai Institutionum Commentarii Quattuor, também conhecidas como Institutas de Gaio, e que foram de grande relevância para a compreensão dos institutos jurídicos romanos do Período Clássico (GIORDANI, 1992, p.1) e as Institutiones que vão compor o Corpus luris Ciuilis no Período Pós-clássico (FRÓES, 2004, p.59).

\section{TRADUZINDO O STATUS JURÍDICO DOS ANIMAIS NAS INSTITUTIONES}

Quando se estuda Direito Romano, o uso do latim tem um caráter técnico e especializado, uma vez que os termos jurídicos se referem a questões muito próprias dos romanos, que só faziam sentido naquele dado momento e perante 
aquelas circunstâncias, não existindo uma exata correspondência entre esses termos nas línguas modernas.

Pode-se recordar, por exemplo, o provérbio italiano traduttore, tradittore (tradutor, traidor) - atribuído a Vittorio Imbriani - para demonstrar a impossibilidade de uma tradução fiel ao texto-fonte.

Muitos autores preferem não traduzir determinadas expressões e vocábulos jurídicos latinos, como mos maiorum, fides, dignitas, honor, gloria, pietas, grauitas, parricidium e princeps, e isto ocorre muito mais por preocupação terminológica do que por qualquer preciosismo linguístico ou busca por erudição (PEREIRA, 1984, p.320-345).

É que muitas traduções realizadas do latim para o português se tornam discutíveis, pois séculos de distanciamento linguístico operam não apenas alterações ortográficas, mas alterações semânticas, sintáticas e pragmáticas.

Por exemplo, embora a expressão "pecunia non olet" seja traduzida corriqueiramente como "o dinheiro não cheira", não se pode esquecer que a noção de pecunia, vocábulo latino derivado de pecus (gado), é mais abrangente que a noção atual de dinheiro.

Outro exemplo, é a expressão "dura lex, sed lex", comumente traduzida como "[...] a lei é dura, mas é a lei", embora a "lex" romana, entendida, por vezes, como constituição imperial, não se confunda com a ideia contemporânea de "lei".

A fim de melhor compreender a força jurídica das Institutas, é preciso ir diretamente à sua versão latina, ao invés de usar como amparo as modernas traduções para o vernáculo, de modo que se escolheu a edição do primeiro volume do conjunto Corpus luris Ciuilis publicada pelo romanista alemão Paulus Krueger, juntamente com Mommsen, Schoell e Kroll (IVSTINIANVS, 2017).

Neste volume foram selecionados os trechos que mencionam os animais, tais como a parte inicial do título II do primeiro Livro, que dispõe sobre questões jurídicas gerais, além de 03 parágrafos do título I do segundo Livro, que versa sobre os tipos de res. 
Formuladas para a cupidade legum iuuentati (para a juventude que ama ler) (CORREIA; SCIASCIA, 1949, p.429), as Institutiones estão escritas de forma simples e objetiva (CRETELLA JÚNIOR, 2004, p.52), com sistematizações ricas em conceitos e classificações, o que as tornam interessantes para a análise teórica do status jurídico dos animais, muito diferente do Digesto, que apresenta um conjunto de soluções esparsas para problemas concretos (PEIXOTO, 1997, p.120).

Ademais, seguindo critérios estabelecidos pelo linguista Roman Jakobson (2003, p.64-65), optou-se por uma tradução interlingual ou propriamente dita do denominado latim tardio ou baixo-latim, que é a língua latina que se passou a falar após a queda do Império Romano.

Além disso, algumas inserções textuais elucidativas foram colocadas entre parênteses para explicar determinadas ocorrências e expressões, mas também para tornar a leitura mais fluida, tendo em vista as inúmeras supressões latinas. Além disso, foram grifadas, em negrito, as passagens consideradas mais importantes da análise.

\section{ANIMAIS COMO SUJEITOS DE DIREITO NATURAL}

Para uma melhor compreensão da pesquisa, serão apresentados quadros textuais com os textos do Corpus luiris Ciuilis traduzidos, seguidos de comentários, para um melhor esclarecimento do status jurídico dos animais no Direito Romano.

Inicialmente é preciso destacar que as Institutas apresenta diversos conceitos e ideias gerais, os quais permeiam toda a obra, além da tradicional tricotomia do direito privado romano: ius gentium, ius naturale e ius ciuile (ANDREOTTI NETO, 1975, p.47)

Conforme a doutrina, o ius gentium (Direito dos Povos) é aquele aplicável nas relações entre estrangeiros em Roma e entre romanos e estrangeiros, em contraste com o ius ciuile (direito civil), que é aplicado apenas entre os romanos e marcado pelo materialismo e formalismo, ao contrário do ius gentium, que é mais flexível e baseado no princípio da boa-fé (fides) (GIORDANI, 1991, p.84). 
O ius naturale (direito natural), por seu turno - visto como uma imposição da natureza e não como uma criação arbitrária do homem - é baseado em normas principiológicas como a "suum cuique tribuere" (dar a cada um o que é seu), "honeste uiuere" (viver honestamente) e "alterum non laedere" (não lesar o outro), assegurando, acima de tudo, o direito à vida, à liberdade e à propriedade (ANDREOTTI NETO, 1975, p.271-272).

Note-se que o jusnaturalismo romano sofre influência do jusnaturalismo grego, utiliza argumentos de ordem filosófico-valorativa como instrumento de justificação do status quo, mas também explicações de natureza cosmológica, tal como referido na tragédia Antígona de Sófocles (CRETELLA JÚNIOR, 2004, p.21).

A partir de Cícero, período republicano, o jusnaturalismo romano vai se difundir a partir da naturalis ratio (razão natural), enquanto imposição de ordem natural que estabelece preceitos jurídicos universalmente concebíveis.

O direito justinianeu, todavia, vai se desenvolver apenas na fase final do direito romano, uma vez que se encontra inserido em um contexto de transição paradigmática, pois, se por um lado, resgata a influência jusnaturalista do período clássico, por outro, acolhe inúmeros elementos da axiologia cristã (CORREIA, SCIASCIA, 1949, p.11).

QUADRO 1: Os Animais No Ivs Naturale, Liv. I, Tit. li

\begin{tabular}{|c|c|}
\hline $\begin{array}{l}\text { LIBER PRIMUS } \\
\text { DE IURE NATURALI ET GENTIUM ET CIVILI } \\
\text { IUs naturale est quod natura omnia animalia } \\
\text { docuit. nam ius istud non humani generis } \\
\text { proprium est, sed omnium animalium, quae in } \\
\text { caelo, quae in terra, quae in mari nascuntur. hinc } \\
\text { descendit maris atque feminae coniugatio, quam } \\
\text { nos matrimonium appellamus, hinc liberorum } \\
\text { procreatio et educatio: videmus etenim cetera } \\
\text { quoque animalia istius iuris peritia censeri. }\end{array}$ & $\begin{array}{l}\text { LIVRO PRIMEIRO } \\
\text { DO DIREITO NATURAL, DAS GENTES E } \\
\text { CIVIL } \\
\text { Direito natural é aquele que a natureza } \\
\text { ensinou a todos os animais. Em verdade, } \\
\text { esse direito não é exclusivo do gênero humano, } \\
\text { mas também se refere a todos os animais que } \\
\text { nascem no céu, na terra e no mar. Dele provém } \\
\text { a união do macho e da fêmea, a que } \\
\text { chamamos casamento. Dele (provém) a } \\
\text { procriação e a educação da prole. Vemos, em } \\
\text { realidade, que também outros animais } \\
\text { qualificam-se pelo conhecimento desse } \\
\text { direito. }\end{array}$ \\
\hline
\end{tabular}

Fonte: autores (2017).

Como se vê no quadro acima, os animais são regulados pelo Direito natural, que repousa em uma diretriz teológica que emana da própria providência divina, pois o jusnaturalismo romano (MARQUES NETO, 2001, p.133-136) reivindica um Direito 
primordial e absoluto, anterior às leis, atemporal, firme, perene, imutável e universal (MACHADO NETO, 1987, p.186-187), visando a preservação de valores como o bem e o justo (BOBBIO, 2006, p.17-18).

O jusnaturalismo romano adota os princípios da liberdade inicial e da isonomia entre todos os homens, de modo que a escravidão ofenderia a própria natureza humana (dominio alieno contra naturam subicitur). ${ }^{1} \mathrm{O}$ processo de inclusão dos escravos decorre muito mais da necessidade de conciliação entre este instituto jurídico e o princípio cristão da igualdade (JOHNSTON, 2004, p.51-52).

Com efeito, o ius naturale é um complexo de leis da natureza que impele aos animais e aos homens práticas semelhantes, tais como alimentação, procriação e a proteção dos filhos. Assim, o direito justinianeu aproxima o animal do ser humano a partir do conceito de alma, característica comum a ambos, embora os animais não sejam considerados seres dotados de espírito ou razão (GORDILHO, 2012, p.144), uma vez que agem apenas por instinto, produzindo sempre ações semelhantes (GIORDANI, 1991, p.93).

Mesmo com a aproximação entre os homens e os animais, para os romanos, face à incapacidade de agir de forma racional, os animais não são considerados sujeitos de direitos e deveres, mas apenas coisas (res) e objetos de direito.

O texto destaca apenas o caráter natural dos fundamentos jurídicos, revelando uma forte influência da filosofia estoica e sua busca por um viver em harmonia com o meio ambiente (PÔRTO, 2017, p.28-29).

Alguns autores discordam desse posicionamento, e consideram que para o direito justinianeu os animais, embora sejam considerados res, possuem direitos de ordem natural, possibilitados pela abundância das fontes, inclusive divergentes, e pelo fato dos romanos serem pragmáticos (MEIRA, 1983, p.49) e não teóricos (CASTRO, 2007, p.83).

Para alguns jurisconsultos romanos, o Direito Natural se refere a todos os animais, racionais e irracionais, algo considerado "surpreendente" e "chocante", razão pela qual esses autores refutam o reconhecimento de qualquer valor jurídico a esse conceito (CRETELLA JÚNIOR, 1971, p.21).

1 Inst. I,3,2. 
Ante isso, é importante destacar um escrito de autoria de Spencer Vampré, um dos maiores romanistas brasileiros do início do século $\mathrm{XX}$, para o qual o texto das Institutas é claro e não deixa dúvidas, no sentido de considerar os animais como sujeitos de direito:

\begin{abstract}
O texto diz claramente que os animais também têm direitos e que o direito natural é comum aos homens e aos animais. Doutrina absurda e insustentável perante o direito moderno. Além disso, não há animais que nasçam no ar. Os intérpretes procuram explicar o conceito do direito natural dizendo que o texto significa que há certos direitos derivados da natureza animal do homem, como a procriação, a legítima defesa etc. e que por isso são chamados naturais; mas o texto é claro e não deixa dúvidas. O Fr. 2 de statu hominum declara que todo o direito é constituído por causa dos homens. Os romanos não viam contradição entre esse texto e o das Institutas, porque entendiam que o direito natural não é constituído, mas preexistente ao homem (VAMPRÉ, 1915, p.5).
\end{abstract}

Também seguindo essa perspectiva, Marita Giménez-Candela reconhece a veneração do Direito Romano à natureza. Assim, considera a existência, inclusive, de um respeito universal pelos animais (GIMÉNEZ-CANDELA, 2017, p.299).

Ocorre, todavia, que muitos intérpretes do Direito Romano adotam uma concepção jurídica anacrônica, transportando valores de uma época para a análise de outra, e é curioso que a doutrina, de modo pacífico, admita uma oposição entre o ius naturale e o ius gentium no tratamento dos escravos, uma vez que os homens são livres por direito natural, pretérito às leis, enquanto a escravidão é admitida pelo direito dos povos, já que instituída pelo homem em seu próprio interesse.

Em suma, para os romanos existe um direito primevo, imposto naturalmente, que pode colidir com os interesses egoísticos de uma determinada comunidade humana, sem, todavia, perder a sua importância universal e atemporal.

Ressalte-se, contudo, que a maior parte da doutrina que aceita a aparente contradição em relação aos escravos, esforça-se para negar o reconhecimento pelos romanos de que os animais possuem direitos de ordem natural.

Os positivistas - na tentativa de superação do jusnaturalismo (MACHADO NETO, 1987, p.333-335) - consideram absurda essa interpretação, e no afã de negar direitos aos animais acabam se tornando vítimas de suas próprias contradições. 
Existe uma certa semelhança entre a interpretação jurídica das Institutiones no que se refere aos interesses dos animais e dos escravos, e uma das distinções feitas por Ulpiano entre o ius gentium e o ius naturale é que a escravidão seria própria do direito das gentes, um instituto que é desconhecido pelo direito natural, pois a liberdade está na essência humana.

O Digesto afirma, inclusive, que "pelo direito natural, todos os homens nascem livres" (IVSTINIANVS, 2017, p.63) (cum iure naturali omnes liberi nascerentur) - o que demonstra uma influência do cristianismo (MARTINS, 2011, p.202) - de modo que a escravidão seria "contrária à natureza" (contra naturam) (IVSTINIANVS, 2017, p.78).

O Pandectas, por seu turno, afirma que o ius gentium se diferencia do ius naturale porque aquele se refere apenas ao comportamento dos homens, enquanto este se refere a todos os animais (sejam eles dotados ou não de razão).

Para o romanista Vampré (1915, p.5), considerar que os animais possuem direitos é algo espantoso em determinadas circunstâncias espaço-temporais, embora os romanos convivam com contradições entre as suas normas de direito privado, e o fato de estarem submetidos a uma cultura pastoril poderia lhes permitir um olhar mais diversificado a respeito dos animais (ANDREOTTI NETO, 1975, p.4445).

Assim, para o Direito Romano, em determinadas situações, os animais são considerados sujeito de direitos em razão do ius naturale - que é um Direito universal, imutável e anterior às leis dos homens (MACHADO NETO, 1987, p.218) -, em outras situações, todavia, eles são considerados res de acordo com o ius ciuile (direito civil), que é um Direito criado pela inteligência humana.

Seja como for, para alguns doutrinadores, o Direito Natural Romano, por influência grega, deriva da razão (ratio naturalis), e seria comum a todos os seres vivos, enquanto outros entendem que o Direito Natural Romano está restrito apenas aos homens (LUIZ, 1981, p.12). 


\section{AQUISIÇÃO DA PROPRIEDADE ANIMAL POR IVS NATVRALE, LIV. II, TIT. I}

QUADRO 2: Aquisição Da Propriedade Animal Por Ivs Natvrale, Liv. li, Tit. I.

\begin{tabular}{|c|c|}
\hline $\begin{array}{l}\text { LIBER SECVNDVS } \\
\text { DE RERVM DIVISIONE } \\
\text { \$11 Singulorum autem hominum multis modis } \\
\text { res fiunt: quarundam enim rerum dominium } \\
\text { nanciscimur iure naturali, quod, sicut } \\
\text { diximus, appellatur ius gentium, quarundam } \\
\text { iure civili. commodius est itaque a vetustiore } \\
\text { iure incipere. palam est autem, vetustius esse } \\
\text { naturale ius, quod cum ipso genere humano } \\
\text { rerum natura prodidit: civilia enim iura tunc } \\
\text { coeperunt esse, cum et civitates condi et } \\
\text { magistratus creari et leges scribi coeperunt. }\end{array}$ & $\begin{array}{l}\text { LIVRO SEGUNDO } \\
\text { DA DIVISÃO DAS COISAS } \\
\text { \$11 Ademais, as coisas se tornam propriedade } \\
\text { de vários modos. Certamente, adquirimos a } \\
\text { propriedade de algumas coisas por direito } \\
\text { natural, o que, como falamos, chama-se } \\
\text { direito das gentes, (enquanto) outras coisas } \\
\text { (adquirimos) por direito civil. É mais } \\
\text { oportuno começar pelo direito mais antigo. É } \\
\text { manifestamente mais antigo o direito } \\
\text { natural, que produziu a natureza das coisas, } \\
\text { como o próprio gênero humano. Certamente, } \\
\text { os direitos civis começaram a existir quando } \\
\text { começaram a ser fundadas as cidades, } \\
\text { nomeados os magistrados e escritas as leis. }\end{array}$ \\
\hline
\end{tabular}

Fonte: O autor (2017).

As Institutas dispõe sobre os animais no início do seu segundo livro, sob o título de "De rerum divisione" (Da divisão das coisas), estabelecendo que os animais são considerados res.

A dificuldade se verifica em relação às palavras res e persona, pois embora elas sejam traduzidas, via de regra, por "coisa" e "pessoa", é preciso destacar que, na atual conjuntura do século $\mathrm{XXI}$, essas formas vernáculas não exprimem exatamente o mesmo sentido de res e persona do século VI, época de Justiniano.

Deve-se evitar uma leitura reducionista que simplesmente identifique os animais como coisa simplesmente porque eles são considerados res, apenas porque este vocábulo é hoje em dia traduzido como "coisa".

Essa consciência linguística é relevante, e serve de base para a compreensão do status jurídico dos animais, que devem ser reconhecidos não apenas como "coisa", mas somos Ostambém como res sui generis (VÉRAS NETO, 2011, p.132).

Juridicamente, considera-se "coisa" o que pode vir a ser objeto de direito subjetivo patrimonial, uma vez que os romanos utilizam tanto os vocábulos pecunia quanto res, (CRETELLA JÚNIOR, 2004, p.107) o primeiro para designar as coisas inseridas no patrimônio de uma determinada pessoa, e o segundo para designar as 
coisas que também estão fora do patrimônio de alguém, como nas expressões res nullius (coisa de ninguém) e res derelicta (coisa abandonada) (CORREIA, 1949, p.42).

Segundo Andreotti Neto (1975, p.63), res significa, em sentido amplo, a patrimonialidade das coisas, enquanto, em sentido estrito, representa a existência de alguma coisa que pode ser sujeita a uma relação jurídica.

De fato, os romanos não possuem uma preocupação muito sistemática no que tange à classificação das res, embora seja possível verificar a existência de uma série de diferenciações, a partir da análise dos textos jurídicos e doutrinários (GIORDANI, 1992, p.69-76).

No Direito Romano as res podem ser classificadas, quanto à dimensão patrimonial, em corpóreas ou incorpóreas, móveis ou imóveis, fungíveis ou infungíveis, simples, compostas ou coletivas, divisíveis ou indivisíveis, principais ou acessórias, frutíferas ou infrutíferas, in commercio ou extra commercium e mancipi ou nec mancipi (FRÓES, 2004, p.143).

As coisas corpóreas, para os romanos, são aquelas que podem ser percebidas pelos órgãos dos sentidos (quae tangi possunt), como os escravos e os animais, enquanto as incorpóreas são imperceptíveis (quae tangi non possunt), a exemplo de direitos (CRETELLA JÚNIOR, 2004, p.110-111).

As coisas móveis (res mobiles), por sua vez, são as que não sofrem alteração na forma ou na substância ao se deslocarem, a exemplo do escravo e do animal que são semoventes (que se movem por si), enquanto são coisas imóveis, o solo e o que mais nele se agregue, como construções e plantações (SERAFINI, 1888, p.107-108).

As coisas fungíveis são aquelas que podem ser substituídas por outras de mesma espécie (ANDREOTTI NETO, 1975, p.66), qualidade e quantidade (res quae pondere numero mensura consistunt), ao passo que as infungíveis, pelo contrário, são as que não se podem substituir por outras, seja por sua natureza singular ou por determinação das partes. O animal, via de regra, é uma coisa fungível, mas ao ser comprado, considera-se as suas qualidades singulares, de modo que uma vaca que produz mais leite do que outras passa a ser considerada uma coisa infungível (CORREIA, 1949, p.42-43). 
Coisa simples é a que forma um todo orgânico, a exemplo de um animal ou de um escravo, e coisa composta é a que forma um todo mecânico, a exemplo de um navio, e por fim, as coisas coletivas são aquelas que integram um todo ideal, como um rebanho (ALVES, 2016, p.148).

Coisas divisíveis são as que se podem fracionar conservando-se a essência e as funções sociais e econômicas, a exemplo de um terreno, mas quando esse fracionamento é impossível passam a ser coisas indivisíveis (quae sine interitu diuidi non possunt) (ANDREOTTI NETO, 1975, p.66), como no caso de um animal ou um escravo.

A classificação em principal e acessório tem um caráter relativo, pois só faz sentido quando uma coisa é considerada em face de outra, de modo que coisa principal é aquela que se une a uma coisa que lhe é dependente, enquanto coisa acessória é justamente a coisa dependente ou subordinada, como os animais domésticos e os escravos (CRETELLA JÚNIOR, 1971, p.118).

Coisas acessórias são aquelas destinadas à cultura do imóvel (instrumenta fundl), e mesmo coisas autônomas podem ser acessórias quando estão a serviço da coisa principal de modo constante e duradouro (ALVES, 2016, p.149).

Coisas infrutíferas são aquelas que não dão frutos, enquanto as frutíferas são aquelas que dão frutos, a exemplo de animais, os quais podem, por vezes, produzir lã e leite, além de filhotes (ANDREOTTI NETO, 1975, p.67).

Coisas in commercio são suscetíveis de ser alienadas ou apropriadas por um particular, a exemplo dos animais e dos escravos, enquanto coisas extra commercium são aquelas que estão fora do comércio, a exemplo das coisas sagradas, religiosas, santas e as coisas comum a todos, como as praças públicas (ALVES, 2016, p.150-151).

Classificação fundamental na República Romana e no início do Principado é aquela que divide as coisas em res mancipi e res nec mancipi (CRETELLA JÚNIOR, 2004, p.110), onde as primeiras são as mais valiosas para os romanos, e se apresentam como numerus clausus, isto é, o ager Romanus, os praedia italica, os escravos, as servidões prediais rústicas, as casas e os animais de carga e tração (bois, cavalos, mulas e asnos), a exceção de camelos e de elefantes (ALVES, 2015, p.153). Todas as demais formam o grupo de res nec mancipi, havendo especial 
atenção para moedas, imóveis em províncias, cabras e carneiros (COGLIOLO, 1889, p.30-37).

Seja como for, é possível afirmar, em síntese, que os animais são considerados res corpórea, móvel, indivisível, in commercio e, via de regra, fungível, simples e frutífera, havendo grande destaque para os animais de carga e tração, que são considerados pelos romanos como res mancipi (aquilo que pode ser seguro pela mão) (SAMPER, 2017, p.47) por sua grande importância para aquele povo agropastoril.

Aspecto bastante curioso refere-se ao fato de que, conforme as Institutiones, no processo de aquisição da propriedade, o ius naturale identificava-se com o ius gentium, em oposição ao ius ciuile (GIORDANI, 1992, p.6).

Essa é, de fato, uma questão controversa entre os romanistas, (PÔRTO, 2017, p.28) e observa-se que a expressão ius gentium (direito dos povos), que se fundamenta na bona fides e na aequitas, (GIORDANI, 1991, p.67) é utilizada em Roma para designar o complexo jurídico-normativo que alicerça as relações entre os próprios estrangeiros ou entre os estrangeiros e os romanos, revestindo-se de menor solenidade do que o ius ciuile, que regula as relações jurídicas entre os cidadãos romanos.

Ocorre que, com o passar do tempo e com a ampliação do Império, a supracitada distinção entre ius gentium e ius ciuile perde sentido, visto que muitos povos são incorporados pelo Império conquistando a cidadania romana (PEIXOTO, 1997, p.229-230).

Assim, a expressão ius gentium vai ganhando, paulatinamente, novos contornos de entendimento e adquirindo um sentido doutrinário (GIORDANI, 1992, p.7) - adotado por Gaio e por Cícero - atrelado à ratio naturalis (razão natural) e entendido mais como um direito universal de todos os povos, o que o aproxima do ius naturale (PÔRTO, 2017, p.33).

Com as Institutas, a compreensão dessas diferenças se torna ainda mais difícil, pois se em alguns momentos fica evidente a distinção tricotômica do direito privado (de iure naturale, et gentium et ciuill), em outros momentos, o direito natural se assemelha ao direito dos povos (iure gentium id est iure naturali) (GIORDANI, 1991, p.89). 
Vicento Sobrinho Pôrto (2017, p.34) expõe que estão registrados em diplomas jurídicos de Direito Romano pelo menos três sentidos diversos para a expressão ius gentium, que pode se referir tanto a um conjunto de normas e institutos aplicáveis nas relações entre peregrinos e romanos ou entre peregrinos em Roma, como a um grupo de normas e institutos fundado na ratio naturalis e aplicável a todos os povos, ou ainda ao agregado de institutos e normas aplicáveis nas relações entre Estados.

As Institutiones consideram que o processo de aquisição da propriedade dos animais pode se operar por ius naturale, a partir dos fundamentos do naturalis ratio (MEIRA, 1983, p.89) (razão natural), de modo que é importante observar como o ius naturale, sobretudo em sua correlação com o ius gentium, enseja efeitos práticos para os romanos, ao disciplinar até mesmo a aquisição da propriedade, uma vez que ele não diz respeito apenas a noções valorativas vagas. 


\section{O STATUS JURÍDICO SUI GENERIS DOS ANIMAIS SELVAGENS E DOMESTICADOS}

QUADRO 3: Reaquisição Da Liberdade Por Animal Selvagem, Liv. li, Tit. I.

\begin{tabular}{|c|c|}
\hline $\begin{array}{l}\text { LIBER SECVNDVS } \\
\text { DE RERUM DIVISIONE } \\
\text { \$12 Ferae igitur bestiae et volucres et pisces, id } \\
\text { est omnia animalia quae in terra mari caelo } \\
\text { nascuntur, simulatque ab aliquo capta fuerint, } \\
\text { iure gentium statim illius esse incipiunt: quod } \\
\text { enim ante nullius est id naturali ratione } \\
\text { occupanti conceditur. nec interest, feras bestias } \\
\text { et volucres utrum in suo fundo quisque capiat, } \\
\text { an in alieno: plane qui in alienum fundum } \\
\text { ingreditur venandi aut aucupandi gratia, potest a } \\
\text { domino, si is providerit, prohiberi, ne ingrediatur. } \\
\text { quidquid autem eorum ceperis, eo usque tuum } \\
\text { esse intellegitur, donec tua custodia coercetur: } \\
\text { cum vero evaserit custodiam tuam et in } \\
\text { naturalem libertatem se receperit, tuum esse } \\
\text { desinit et rursus occupantis fit. naturalem } \\
\text { autem libertatem recipere intellegitur, cum } \\
\text { vel oculos tuos effugerit vel ita sit in } \\
\text { conspectu tuo, ut difficilis sit eius persecutio. }\end{array}$ & $\begin{array}{l}\text { LIVRO SEGUNDO } \\
\text { DA DIVISÃO DAS COISAS } \\
\text { §12 Assim, os animais selvagens, as aves e os } \\
\text { peixes, isto é, todos os animais que nascem na } \\
\text { terra, no mar e no céu, que tiverem sido } \\
\text { capturados por alguém, passam a ser deste } \\
\text { imediatamente, por direito das gentes, visto } \\
\text { que o que antes não era de ninguém, é } \\
\text { concedido, pela razão natural, a quem o } \\
\text { possui. Não importa que alguém capture os } \\
\text { animais selvagens e as aves em sua } \\
\text { propriedade ou em propriedade alheia. Sem } \\
\text { dúvida, aquele que entra em propriedade alheia } \\
\text { com o escopo de caçar ou de capturar aves } \\
\text { pode ser proibido pelo dono, se ele (o dono) } \\
\text { pressentir que certamente (o invasor) entraria. } \\
\text { Mas se você tiver capturado qualquer um deles } \\
\text { (dos animais), ele (o animal) é considerado } \\
\text { seu, enquanto estiver retido sob sua custódia. } \\
\text { Mas quando evadir de sua custódia e se } \\
\text { refugiar na liberdade natural, deixa de ser } \\
\text { seu e se faz novamente daquele que o } \\
\text { possuir. Ademais, entende-se por } \\
\text { "recuperar a liberdade natural” quando tiver } \\
\text { escapado de seus olhos ou, estando em sua } \\
\text { presença, seja difícil a sua persecução. }\end{array}$ \\
\hline
\end{tabular}

Fonte: O autor (2017).

Inicialmente, o primeiro título do livro I das Institutas apresenta os diversos tipos de coisas e, a partir do parágrafo 12, começa a descrever as formas de aquisição da propriedade pelo ius gentium. Já nesse parágrafo, explicitado no Quadro 3, os animais passam a ganhar maior destaque, o que se justifica pela relevância atribuída pelos romanos a essas criaturas, tendo em vista a sua cultura agropastoril (GASSEN, 2011, p.178-179).

O status jurídico dos animais é tão particular nessa cultura que varia conforme o tipo de animal, uma vez que os romanos diferenciam, na República e no início do Principado, alguns animais em res mancipi e res nec mancipi (FRÓES, 2004, p.143), havendo destaque para os de carga e tração, pertencentes ao primeiro grupo. 
Outra distinção a ser considerada diz respeito a natureza do animal que pode ser selvagem ou doméstica, distinção que se constituí em importante critério para determinar a aquisição ou a perda da propriedade.

A classificação de "animal selvagem" fragilizava o vínculo de propriedade, diferentemente da classificação de "animal doméstico", (CRETELLA JÚNIOR, 1971, p.118) cuja tendência é que o vínculo perdure. Se o animal for considerado selvagem se torna mais fácil a perda da propriedade, como nos casos de fuga. ${ }^{2}$

As abelhas, por exemplo, são consideradas selvagens por natureza e, dessa forma, são de difícil aquisição, uma vez que ela não se opera pelo simples pouso em uma árvore na propriedade de alguém. ${ }^{3}$

Além disso, qualquer outra pessoa pode ser proprietário das abelhas que pousem na árvore de um determinado imóvel, podendo o dono do imóvel, contudo, impedir a entrada do estranho em suas terras (VAMPRÉ, 1915, p.61-62).

Diante do exposto, observa-se que um animal selvagem sem dono é considerado res nullius (coisa de ninguém) (CORREIA; SCIASCIA, 1949, p.42), e pode ser apropriado por quem o capture, não importando se isso seja feito em propriedade privada ou em um lugar em que a presença do invasor possa ser impedida.

Não é por acaso que, no supramencionado trecho, as Institutiones empregam, em relação aos animais uma expressão do ius gentium, pois considera a sua concepção doutrinária atrelada a naturalis ratio (MACHADO NETO, 1987, p.230).

A inserção do animal em um jogo simétrico de liberdades, por um lado autoriza a aquisição da propriedade do animal através da captura, mas, por outro, também reconhece a reaquisição de sua liberdade nas hipóteses de fuga, mesmo que diante dos olhos do proprietário ou quando for difícil a sua persecução.

2 SAMPER, 2017, p.89: "Mas o que se diz a respeito dos animais que podem ser domados são res mancipi se pergunta como se deve interpretar, já que não são domados imediatamente quando nascem. Os professores de nossa escola consideram que se tornavam res mancipi no instante em que nasciam. Nerva e Próculo, ao contrário, e professores de outra escola consideram que eram considerados res mancipi apenas aqueles que podiam ser domados, e se devido à sua excessiva selvageria não podiam sê-lo, então começavam a ser res mancipi no momento em que alcançavam a idade de serem domados. As feras eram nec mancipi, como por exemplo, os ursos, os leões [...]" (Tradução nossa).

3 Inst. II, 1, 14. 
A despeito do Digesto considerar que todos os seres humanos são livres por ius naturale, um escravo foragido, diferentemente de um animal selvagem, não readquire sua liberdade com a fuga.

Há, dessa forma, o reconhecimento tácito de que o lugar genuíno dos animais é a natureza, onde eles podem desfrutar de um direito de liberdade, e esta é mais uma razão pelas quais possamos afirmar que os animais possuíam um status jurídico sui generis nas Institutiones (ALVES, 2016, p.148).

\section{AQUISIÇÃO DA LIBERDADE POR ANIMAL DOMESTICADO}

QUADRO 4: Aquisição Da Liberdade Por Animal Domesticado, Liv. li, Tit. I.

\section{LIBER SECVNDVS}

DE RERUM DIVISIONE

$\$ 15$ Pavonum et columbarum fera natura est. nec ad rem pertinet, quod ex consuetudine avolare et revolare solent: nam et apes idem faciunt, quarum constat feram esse naturam: cervos quoque ita quidam mansuetos habent, ut in silvas ire et redire soleant, quorum et ipsorum feram esse naturam nemo negat. in his autem animalibus, quae ex consuetudine abire et redire solent, talis regula comprobata est, ut eo usque tua esse intellegantur, donec animum revertendi habeant: nam si revertendi animum habere desierint, etiam tua esse desinunt et fiunt occupantium. revertendi autem animum videntur desinere habere, cum revertendi consuetudinem deseruerint.

Fonte: O autor (2017).

\section{LIVRO SEGUNDO \\ DA DIVISÃO DAS COISAS}

§15 É selvagem a natureza dos pavões e das pombas. Não importa ao caso que costumem sair e regressar voando, pois, em realidade, o mesmo fazem as abelhas, cuja natureza é selvagem. Igualmente, alguns têm também cervos domesticados, que costumam ir para os bosques e regressar, dos quais ninguém nega (entretanto) que sejam de natureza selvagem. Mas a respeito desses animais que costumam ter o hábito de ir e voltar, estabeleceu-se a regra: entende-se que são seus enquanto tenham o ânimo de voltar, pois se tiverem deixado de ter o ânimo de voltar, deixam também de ser seus e se submetem a (novos) possuidores. Além disso, considera-se que deixaram de ter o ânimo de voltar quando tiverem abandonado o costume de voltar.

Já foi esclarecida a importância da classificação dos animais em domésticos e selvagens (CRETELLA JÚNIOR, 1971, p.118), e diante disso, deve-se questionar qual seria o critério adotado para se saber a qual grupo um animal pertenceria.

Os romanos classificavam os animais (ALVES, 2016, p.148) a partir da natureza do convívio com seres humanos, muito além de seu simples hábito de ir e voltar, e as Institutiones, razão pela qual considera abelhas e cervos como selvagens, ainda que tenham o costume de regressar (VAMPRÉ, 1915, p.62). 
Além da divisão em selvagens e domésticos (CRETELLA JÚNIOR, 1971, p.118) pode-se classificar os animais em possuidores ou não do hábito de retornar, onde os animais que possuem esse hábito são considerados - em geral, mas não necessariamente - animais domesticados.

Para as Institutiones, os animais portadores desse hábito integram o patrimônio de alguém enquanto perdurar esse animus reuertendi (ânimo de regressar), e merece destaque o uso da palavra animus em relação aos animais.

No latim, tal vocábulo significa ânimo, desejo, mente, coração, alma, intenção, consciência, sentimento, atenção, memória, pensamento, imaginação e intento, dentre outros, (DICIONÁRIO, 2001, p.63) uma vez que os romanos usam expressões como animus domini, animus donandi, animus furandi, animus nouandi, animus possidendi e animus societatis, expressões que estão vinculadas à uma noção de vontade ou desejo (PEIXOTO, 1997).

$\mathrm{O}$ animus reuertendi deve ser objetivamente examinado, através da análise do comportamento externado pelo animal, não a partir de uma investigação psicológica. Contudo, em vários outros casos referentes a pessoas, sobretudo em relação ao direito privado, também não se faz um mergulho na análise subjetiva do elemento anímico (ALVES, 2016, p.274-279).

Dessa forma, o critério adotado para efeito de perda da propriedade está centrado no ânimo animal, não no comportamento do dono, por exemplo, descuido ou negligência que propiciem a fuga do animal.

Aristóteles defendia a "grande cadeia da vida", segundo a qual os seres vivos seriam diferenciados, conforme sua mera capacidade de sobrevivência (plantas), aptidão para consciência e senciência (animais), espiritualidade (homens) e os de degraus mais elevados (divindades) (GORDILHO, 2012, p.152).

Outro aspecto que desperta curiosidade é que o dono pode perder o seu direito de propriedade sem que outra pessoa o adquira de imediato e sem que ele necessariamente o queira, já que esse fato considerado como abandono e a coisa se torna res derelicta (PEIXOTO, 1997, p.370).

Isso ocorre quando o animal selvagem readquire a liberdade natural (quadro 3) ou quando o animal domesticado perde o seu animus reuertendi (quadro 4) (ALVES, 2016, p.328) estando o ânimo dos animais diretamente vinculado a 
determinados efeitos jurídicos, de modo que os animais selvagens e domesticados suem direitos derivados do ius naturale, o que significa que eles possuem um status jurídico sui generis.

\section{CONCLUSÃO}

Os romanos desenvolveram uma relação muito própria com os animais, que eram considerados importantes naquela sociedade agropastoril, oferecendo um tratamento específico a essas criaturas.

Para entender o status jurídico dos animais nas Institutiones foi preciso revisitar a história do direito justinianeu e constatar que os romanos eram homens práticos que tinham uma dificuldade teórica muito grande em manter um sistema jurídico harmônico e destituído de contradições.

Para compreender o status dos animais nas Institutiones do Corpus luris Ciuilis, esta pesquisa utilizou a edição, em latim, do alemão Paulus Krueger, e em diálogo com vários romanistas demonstrou que os animais possuíam um status jurídico sui generis, uma vez que eles eram juridicamente diferenciados das demais coisas pelo animus e vontade.

Observou-se, ainda, que a divisão do direito privado romano em ius ciuile, ius gentium e ius naturele, possibilitou entendimentos contraditórios, uma vez que foram encontrados traços indicadores de que os animais eram titulares de alguns direitos derivados da ordem natural, especialmente o direito de liberdade.

\section{REFERÊNCIAS}

ALVES, José Carlos Moreira. Direito romano. 17. ed. Rio de Janeiro: Forense, 2016.

AMARO, Chico. O neoliberalismo só quer o conhecimento rentável. Terra Vermelha, Londrina, n.48, p.7, abr. 2003.

ANDREOTTI NETO, Nello. Direito civil e romano. 2. ed. São Paulo: Riddel, 1975. 
ÁROSTEGUI, JULIO. A Pesquisa Histórica: teoria e método. Tradução: Andréa Dore. Bauru: Edusc, 2006.

BOBBIO, Norberto. O Positivismo Jurídico. Lições de Filosofia do Direito. Tradução: Márcio Pugliesi. São Paulo: Ícone, 2006.

BONFANTE, Pietro. Istituzioni di Diritto Romano. 6. ed. Milano: Dottor Francesco Vallardi, 1919.

CAMPELLO, Manoel Netto Carneiro. Direito Romano: Prelecções expendidas em aula. 2. ed. Rio de Janeiro: Francisco Alves \& Cia. v. 1. 1929.

CASTRO, Flávia Lages de. História do Direito Geral e do Brasil. 5. ed. Rio de Janeiro: Lumen Juris, 2007.

CHALFUN, Mery. Animais, Manifestações Culturais e Entretenimento: Lazer ou Sofrimento? Instituto Abolicionista Animal. Salvador. Disponível em: $<$ http://www.abolicionismoanimal.org.br/artigos.php?pageNum_artigos=0\&totalRows _artigos $=69 \& \operatorname{cod}=16>$ Acesso em: 04/08/2017, p. 1-2.

CHAMOUN, Ebert. Instituições de Direito Romano. 5. ed. São Paulo: Forense, 1968.

COGLIOLO, Pietro. Diritto Privato Romano. Firenze: G. Barbèra, Editore, 1889, v. 2.

CORREIA, Alexandre; SCIASCIA, Gaetano. Manual de Direito Romano: e textos em correspondência com os artigos do código civil brasileiro. São Paulo: Saraiva, 1949.

CRETELLA JÚNIOR, José. Curso de direito romano. 29. ed. Rio de Janeiro: Forense, 2004.

Curso de direito romano: $O$ direito romano e o direito civil brasileiro no Novo Código Civil. 30. ed. Rio de Janeiro: Forense, 2007.

Forense, 1971.

Direito Romano Moderno: Complemento ao Curso. 1.ed. Rio de Janeiro:

DICIONÁRIO. Latim-português. 2. ed. [S.I.] Porto editora, 2001, p.63.

FRÓES, Oswaldo. Direito Romano: Essência da Cultura Jurídica. São Paulo: Editora Jurídica Brasileira, 2004.

GADAMER, Hans-Georg. A linguagem como médium da experiência hermenêutica. In: Verdade e método I. Trad. Flávio Paulo Meurer. Petrópolis: Vozes. 1997.497631. 
GASSEN, Valcir. A natureza histórica da instituição do direito de propriedade. In: WOLKMER, Antonio Carlos (Org.). Fundamentos de História do Direito. 6.ed. Belo Horizonte: Del Rey, 2011. p. 169-193.

GIMÉNEZ-CANDELA, Marita. La descosificación de los animales. Revista Eletrônica do Curso de Direito - UFSM. v. 12, n. 1 / 2017 p. 298-313.

GIORDANI, Mário Curtis. Iniciação ao Direito Romano. 2. ed. Rio de Janeiro: Lumen Juris, 1991.

1992.

. O Código Civil à Luz do Direito Romano. 1. ed. Rio de Janeiro: Forense,

. Romanos e Partos: Atividades Bélicas na República e no Principado.

Saeculum: Revista de História [13]; João Pessoa, jul/dez. 2005.

GORDILHO, Heron José de Santana. Abolicionismo Animal. Salvador: Evolução, 2008.

.Why animals are spiritual beings? Revista Brasileira de Direito Animal RBDA v. 10 - jan./jun. 2012, p. 139-174.

HENRIQUE, João. Direito Romano. Porto Alegre: Livraria do Globo, 1938.

IVSTINIANVS, Flavius Petrus Sabbatius. Digesto ou Pandectas do Imperador Justiniano. Tradução: Manoel da Cunha Lopes e Vasconcellos (Conselheiro Vasconcellos) et al. 1. ed. São Paulo: YK Editora, 2017.

Corpus luiris Ciuilis. Disponível em: https://bibdig.biblioteca.unesp.br/handle/10/6423. Acesso em 13/03/2017.

Institutas do Imperador Justiniano: manual didático para uso dos estudantes de direito de Constantinopla, elaborado por ordem do Imperador Justiniano, no ano de 533 d.C. tradução J. Cretella Jr. E Agnes Cretella - 2. ed. ampl. e rev. da tradução. - São Paulo: Editora Revista dos Tribunais, 2005.

JAKOBSON, R. Linguística e Comunicação. Tradução de Izidoro Blikstein e José Paulo Paes. São Paulo: Cultrix, 2003.

JOHNSTON, David. Roman Law in Context. Cambridge University Press, 2004.

LIMA FILHO, Acacio Vaz de. As Constituições Imperiais como Fonte do Direito Romano. São Paulo: Ícone, 2006.

LOPES, José Reinaldo de Lima; QUEIROZ, Rafael Mafei Rabelo; ACCA, Thiago dos Santos. Curso de História do Direito. 3. ed. São Paulo: MÉTODO, 2013.

LUIZ, Antônio Filardi. Curso de Direito Romano. 3. ed. São Paulo: Atlas, 1999. 
Noções de Direito Romano. [S.I.: s.n], 1981.

MACHADO NETO, Antônio Luís. Sociologia Jurídica. 6. ed. São Paulo: Saraiva, 1987.

MARQUES NETO, Agostinho Ramalho. A Ciência do Direito. Conceito, Objeto e Método. 2. ed. Rio de Janeiro: Renovar, 2001.

MARTINS, Argemiro Cardoso Moreira. O direito romano e seu ressurgimento no final da idade média. In: WOLKMER, Antonio Carlos (Org.). Fundamentos de História do Direito. 6. ed. Belo Horizonte: Del Rey, 2011. p. 195-230.

MENDES, Renat Nureyev; REIS, Jair Teixeira dos. Entre a Formação Humanista e a Tecnicista: Perspectivas do Ensino Jurídico e do Bacharelismo no Brasil - Do Auge Ao Declínio, Revista da Faculdade de Direito - RFD-UERJ - Rio de Janeiro, n. 30 , dez. 2016.

MEIRA, Raphael Corrêa de. Curso de Direito Romano. São Paulo: Saraiva, 1983.

MOMMESEN, Teodoro. Derecho penal romano. Bogotá: Temis, 1976.

NÓBREGA, Vandick L. Da. Compêndio de Direito Romano. 9. ed. Vol. I. Rio de Janeiro:Freitas Bastos S.A, 1977.

PEIXOTO, José Carlos de Matos. Curso de Direito Romano. Rio de Janeiro: Editorial Peixoto, S.A., 1943. v. 1.

. Curso de Direito Romano. 4. ed. Rio de Janeiro: Renovar, 1997.

PEREIRA, Maria Helena da Rocha. Estudos de História da Cultura Clássica. Lisboa: Fundação Calouste Gulbenkian, 1984. v. 2.

PÔRTO, Vicente Sobrinho. Direito Romano: Comentários a textos do Livro I das Institutas de Justiniano. 2. ed. Rio de Janeiro: Livraria Freitas Bastos S.A. 1962.

RADDING, Charles; CIARALLI, Antonio. The Corpus luris Ciuilis in the Middle Ages. Boston, 2007.

RICCOBONO, Salvatore. Roma, madre de las leyes. Trad. J.J. Santa-Pinter. Buenos Aires: Depalma, 1975.

SAMPER, Francisco. Las instituciones de Gayo. Santiago: Ediciones Universidad Católica de Chile. 2017.

SCHILLER, A. Arthur. Roman Law: Mechanisms of Development. New York: Mouton. 1978.

SERAFINI, Filippo. Istituzioni di Diritto Romano. Quarta Edizione. Firenze: Giuseppe Pellas, Editore, 1888, v.1 
STEIN, Peter. Roman Law in European History. Cambridge University, 2004.

TELLEGEN-COUPERUS, Olga. A Short History of Roman Law. Taylor \& Francis e-Library, 2003 .

VAMPRÉ, Spencer. Institutas do Imperador Justiniano. São Paulo: Livraria Magalhães, 1915.

VÉRAS NETO, Francisco Quintanilha. Direito Romano Clássico: seus institutos jurídicos e seu legado. In: WOLKMER, Antonio Carlos (Org.). Fundamentos de História do Direito. 6. ed. Belo Horizonte: Del Rey, 2011. p. 131-165. 